\title{
Accuracy of single-breath counting test to determine slow vital capacity in hospitalized patients
}

Anna Luiza Escóssio' https://orcid.org/0000-0003-0202-5976

Rodrigo Cappato de Araújo ${ }^{1}$

https://orcid.org/0000-0002-6399-3201

Nicole Oliver ${ }^{1}$

https://orcid.org/0000-0003-0546-6152

Emília Chagas Costa ${ }^{1}$ https://orcid.org/0000-0002-7664-5994

José Ângelo Rizzo'

https://orcid.org/0000-0002-5997-9036

Emanuel Sávio Cavalcanti Sarinho'

https://orcid.org/0000-0003-3331-6274

Yossef Aelony 1

https://orcid.org/0000-0002-8826-2173

Marco Aurélio de Valois Correia Junior ${ }^{1}$

https://orcid.org/0000-0003-0386-5256

Universidade de Pernambuco - UPE, Petrolina, Pernambuco, Brasil.

Conflict of interests: Nonexistent

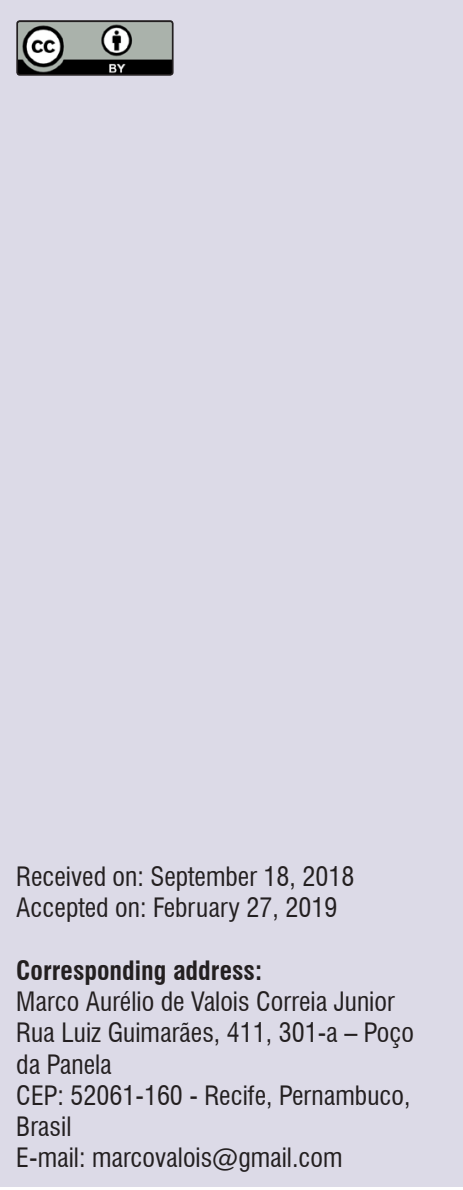

\section{ABSTRACT}

Purpose: to identify the accuracy of the single-breath counting test to determine slow vital capacity in hospitalized patients and to evaluate the repeatability of the same examiner.

Methods: a diagnostic study and the choice of techniques were randomly assigned. The area under the curve (receiver operating characteristic) was calculated from the slow vital capacity $(20 \mathrm{ml} / \mathrm{kg})$ to evaluate the best psychometric characteristics of single-breath counting Test for this cutoff point. Repeatability observed by the same examiner was assessed using the Intraclass Correlation Coefficient.

Results: 516 patients hospitalized for various diseases were analyzed. In the curve analysis (receiver operating characteristic/slow vital capacity $=20 \mathrm{ml} / \mathrm{Kg}$ ), the value of 21 in single-breath counting test with a sensitivity of $94.44 \%$ and specificity of $76.62 \%$ (area under the curve $=0.93, p<0.005$ ) was found. The intraclass correlation coefficient value for the single-breath counting test was 0.976 with $p>0.005$.

Conclusion: the single-breath counting test was a valid and repetitive technique, and may be an important screening option for assessment of lung function in the absence of specific equipment. This technique opens perspectives to replace slow vital capacity measurement in hospitals, which lack spirometric equipment, or in patients who may have a contagious disease, which has a risk of contamination and spread of disease from one patient to another.

Keywords: Spirometry; Lung Diseases; Vital Capacity; Phonation 


\section{INTRODUCTION}

Measurements of lung volumes are used in clinical practice in order to screen for functional abnormalities and to estimate the degree of loss of pulmonary function $^{1-9}$. One of these volumes is the slow vital capacity (SVC), defined as the largest amount of air a person can exhale, slowly, after a maximal inspiration ${ }^{2,3,6}$. A complete pulmonary functional evaluation includes many other measurements ${ }^{7}$, but we have been investigating the SVC and the single-breath counting test (NC abbreviation for numerical counting) as quantitative screening tools for obstructive or restrictive processes in circumstances where more refined and costly equipment to measure functional deficits are not available ${ }^{10-12}$. We have also studied the utility of the maximal phonation time (MPT). We would like to better define the practical utility of NC \& MPT in our Brazilian hospital. This study seeks to define how well NC may correlate with spirometric through the validity of the NC from a slow vital capacity value previously set and repeatability by the same examiner.

\section{METHODS}

This research was conducted on the hospital wards and the intensive care unit in a reference public hospital in the city of Petrolina, Brazil, from May 2012 to January 2014 after approval by the Ethics Committee of Universidade de Pernambuco under the Number 478.571(CAAE: 20222613.5.0000.5207). It is part of a larger study that analyzes the behavior of the slow vital capacity and the maximum phonation time of a research group of the cardiopulmonary laboratory of the University. All volunteers were informed about the research objectives as well as their rights as participants and signed an informed consent.

This was a diagnostic study and the order of the tests execution (spirometry technique and numerical count) were performed randomly (simple draw). All procedures were performed by previously trained researchers.

Study participants were hospitalized individuals of both sexes aware, aged 18-80 years and presenting with lung diseases, neurological, oncological, cardiac, hepatic, infections and postoperative of general surgery. Exclusion criteria were hemodynamically unstable individuals, respiratory rate above 30 breaths per minute, signs of hypoxemia (SpO2 <90\%), asthma attacks and in patients who could not conduct the investigation because of pain or failure to understand the performing technique. Patients whose medical record or interview suggested inflammatory disease, infection or injury in the upper respiratory tract were also excluded. The assessment would be interrupted if the patient had any discomfort during the procedure or if any parameter described in exclusion criteria was found after the tests started (no patient was discontinued).

Individual variables measured were height, total body mass (TBM), age, gender, cause of hospitalization, slow vital capacity and numerical counting. Evaluator following the standardization of the International Society for the Advancement of Kinanthropometry $(\text { ISAK })^{13}$ conducted the measurement of TBM and height. For both measurements, we used digital scale (G-TECH, Pernambuco, Brazil) and tape (Joamarca, São Paulo, Brazil). The age, sex and cause of hospitalization variables were obtained from medical records or interview. The SVC was measured by the MicroQuarck spirometer (Cosmed - Italy).

Spirometry is a validated method used throughout the world as a reference standard for assessing slow vital capacity for many years ${ }^{2}$. In the evaluation the subject was instructed to make a maximal inspiration to reach total lung capacity and then to blow all the air through on the device slowly until reaching the residual volume. We chose the best measurement from three attempts, with a rest period of two minutes between each maneuver ${ }^{2,11,12}$. To perform the calculation of SVC by relative form was used the following equation $[$ female $=45+0.93 \times$ (height -152.4 ); Man $=50+$ $0.91 \times$ (height - 152.4) $]^{11,12}$. The value categorized from $20 \mathrm{ml} / \mathrm{kg}$ was chosen as the cutoff point for evaluating the receiver operator characteristic curve (ROC), because a SVC below this value was described as need for intervention.

We then estimated the SVC by the technique of counting numbers (NC). The individual was asked to inspire as much air as possible and during exhalation begin to counting numbers in ascending order, beginning with the numeral one to the greatest number that he/she could reach in a single exhalation ${ }^{11,12}$. The value chosen for analysis also was the best in three attempts, following a one-minute rest between measurements. The rest time between one technique and another one was five minutes and during test (SVC and NC) the patients were instructed to stay in bed in the sitting position.

Repeatability of the NC and SVC were performed by the same researcher and the choice of techniques were 
conducted randomly in the first and second evaluation, with a minimum interval of six hours and a maximum of eight hours after the first evaluation. Repeatability was performed in the first stage of the study in the first 70 patients. This sample size is described as sufficient for repeatability studies with good statistical power.

\section{Statistical Analysis}

The data were processed and analyzed using the Graph Pad Instat program (Graph Pad Inc., San Diego, USA, Release 3:06, 2003). Initially were subjected to normality criteria (Kolmogorov-Smirnov test). Mean and standard deviation (SD) were used to present continuous variables, while categorical data were presented by absolute and relative frequencies. Bilateral $p$ values were calculated, and the significance level was $5 \%$.

To assess the cutoff point of numerical counting technique, a ROC curve was plotted and the area under the curve was calculated. Was established as the best cut point for the NC one with the highest sum of sensitivity and specificity ${ }^{14}$. From the value found in NC we calculated the positive predictive value, negative predictive value, positive likelihood ratio and negative likelihood ratio.

For the evaluation of test-retest was used the Intraclass Correlation Coefficient (ICC), the intra-examiner method and the standard error of measurement was calculated from the formula: SEM: SD $\sqrt{ }(1-I C C)$, where SD is the standard deviation of mean at baseline; and ICC value was derived from testretest reliability ${ }^{15}$.

\section{RESULTS}

Evaluations were made on 516 hospitalized individuals with different causes of hospital admission and $54 \%$ (270) were male and $46 \%$ (246) female. The mean age $( \pm S D)$ was $37 \pm 31.11$ years. The general characteristics of the sample are shown in Table 1.
Table 1. General characteristics of the sample

\begin{tabular}{lc}
\hline Variáveis & Hospitalizados ( $\mathbf{n}=\mathbf{5 1 6}$ ) \\
\hline Age (years) & $37 \pm 31.11$ \\
TBM (kg) & $58 \pm 10.8$ \\
Ideal weight $(\mathrm{kg})$ & $61.4 \pm 3.3$ \\
Height $(\mathrm{m})$ & $1.66 \pm 9.2$ \\
SVC (ml) & $3235 \pm 1746$ \\
SVC (ml/kg) & $51.4 \pm 30.3$ \\
NC (counting) & $27 \pm 18.3$ \\
Gender & \\
$\quad$ Females & $246(46 \%)$ \\
$\quad$ Males & $270(54 \%)$ \\
\hline Clinical diagnosis & \\
$\quad$ Lung diseases & $76(14.7 \%)$ \\
Heart diseases & $98(18.9 \%)$ \\
Oncologial diseases & $33(6.3 \%)$ \\
Neurological diseases & $42(8.1 \%)$ \\
Liver diseases & $37(9.8 \%)$ \\
Urinary diseases & $34(7.1 \%)$ \\
PO trauma surgery & $86(16.6 \%)$ \\
PO cardiac surgery & $39(7.5 \%)$ \\
PO abdominal surgery & $71(10.4 \%)$ \\
\hline
\end{tabular}

Data are expressed as mean \pm standard deviation or absolute numbers (\%). TBM = Total body mass; SVC = slow vital capacity; NC = number counting technique; $\mathrm{PO}=$ postoperative. $\mathrm{M}=$ meters $\mathrm{Ml}=$ millimeters .

Figure 1 shows the value of the numerical count technique 21 found through the analysis of the ROC curve for the categorized SVC value of $20 \mathrm{ml} / \mathrm{kg}$ with a sensitivity of $94.44 \%$, a specificity of $76.62 \%$ and area under the ROC curve of $0.93(95 \% \mathrm{Cl}, 0.90$ to $0.96 ; p$ $<0.005$ ). The predictive values (positive and negative), accuracy, and likelihood ratio values (positive and negative) are in Table 2.

The intra-rater reliability is demonstrated by intraclass correlation coefficient (ICC) and standard error of measurement (SEM). The results showed excellent intra-rater reliability as counting technique as SVC (Table 3). 


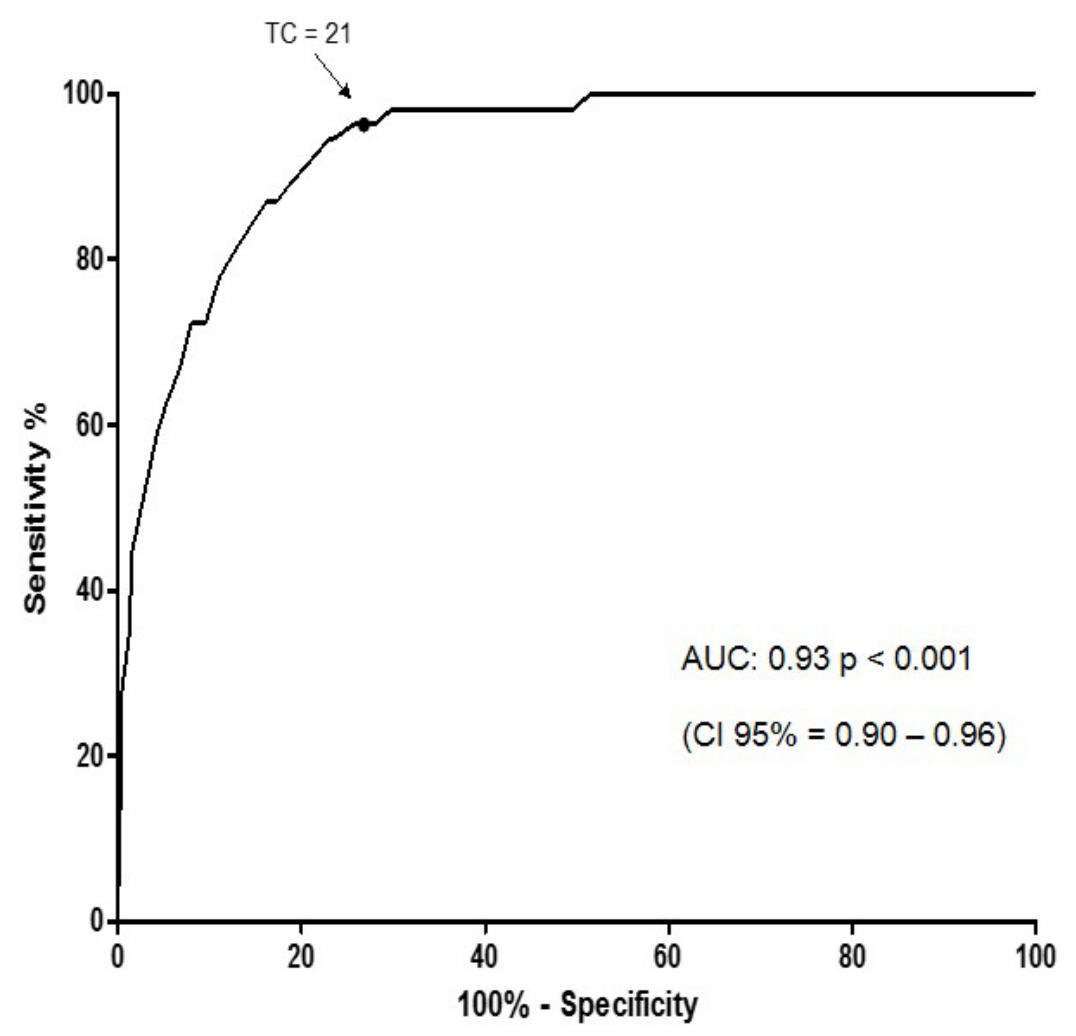

Figure 1. Area under the curve from Numerical Counting technique for predicting the Slow Vital Capacity in hospitalized patients. TC = Counting Technique; AUC = Area Under the Curve; $\mathrm{Cl}=$ confidence interval.

Table 2. Sensitivity, specificity, predictive values and likelihood of numerical counting technique for a vital capacity of 20 millimeters / kilogram

\begin{tabular}{cccccccc}
\hline Cutoff point & SEN & ESP & ACC & PPV & NPV & PLR & NLR \\
\hline NC $=21$ & 94.44 & 76.62 & 78.49 & 32.08 & 99.16 & 4.04 & 0.07 \\
\hline
\end{tabular}

NC = Numerical Count technique; SEN: sensitivity; ESP: specificity; ACC: accuracy; PPV: positive predictive value; NPV: negative predictive value; PLR: positive likelihood ratio; NLR: negative likelihood ratio.

Table 3. Intra-rater reliability through the intraclass correlation coefficient and standard error of measurement in the first 70 patients evaluated

\begin{tabular}{ccccc}
\hline & Evaluator Moment 1 & Evaluator Moment 2 & ICC (CI 95\%) & SEM \\
\hline NC & $28.37 \pm 16.87$ & $26.86 \pm 16.65$ & $0.976(0.961-0.985)$ & 0.80 \\
SVC ml & $2619.56 \pm 1025.95$ & $2424.49 \pm 1029.23$ & $0.962(0.938-0.976)$ & 14.99 \\
SVC ml/Kg & $43.28 \pm 13.84$ & $40.11 \pm 14.76$ & $0.950(0.919-0.969)$ & 031 \\
\hline
\end{tabular}

$\mathrm{NC}=$ Numerical Count technique; SVC = slow vital capacity; ICC = interclass correlation coefficient; $\mathrm{SEM}=$ Standard Measurement Error; $\mathrm{Cl}=$ confidence interval; $\mathrm{ML}=$ millimeters; $\mathrm{Kg}=$ kilogram 


\section{DISCUSSION}

This study showed that the numerical count technique in hospitalized individuals presented a good validity with the Slow Vital Capacity (SVC) and excellent intra-examiner repeatability. It can be useful for evaluation of lung function with Numerical Count Technical values (NC) lower 21, reflecting an SVC below $20 \mathrm{ml} / \mathrm{kg}$. This research suggests that in the absence of specific equipment, the NC may be a good screening option for a more specific test, because the patients classified with a NC under $21,94.44 \%$ were with a SVC below $20 \mathrm{ml} / \mathrm{kg}$, which would indicate a possible need therapeutics ${ }^{5}$. However, it was not a specific test because the positive predictive value indicated that among patients with altered NC, the probability of SVC altered was only $32 \%$. In addition, some individuals classified with a possible limitation in the test, could have no problem (specificity $=76.62 \%$ ), being important the diagnostic confirmation.

Individuals hospitalized can have decreased SVC regardless of the reason that led to hospitalization, and identify this functional limitation in various diseases, can help treat them adequate ${ }^{3-5,16-18}$. Vital capacity lower than $20 \mathrm{ml} / \mathrm{kg}$ is described in the literature ${ }^{5}$ as an important value to trace possible interventions in patients regardless of the related disease, confirming the purpose of this research that does not separate individuals by disease, indicating that simply viewing a decrease in these values for starting treatment.

As the lung function is directly related to voice production, individuals with lung disease may have changed MPT and reduction in the amount of air available to support phonation ${ }^{11,12,19}$. Some researchers just associated the MPT with the inspiratory peak flow ${ }^{20}$ and $\mathrm{VO}_{2}{ }^{21}$, however, associations between MPT and the SVC is relatively recent in the literature. Two Brazilian studies found a positive correlation between SVC and NC in healthy individuals ${ }^{11}$ and hospitalized ${ }^{12}$, found a much higher correlation in hospitalized. This finding had already been reported by the study Toyoda et al. ${ }^{22}$ who found no correlation in healthy subjects, however the authors did not evaluate the MPT by NC. Healthy individuals may not have presented good correlation in previous studies because despite the anthropometric characteristics of each individual vary, the value show little variation, showing proportionality, unlike hospitalized patients with very different values for both the SVC and MPT.

Latronico et al. ${ }^{16}$, reported that a rough estimate of the SVC could be done by counting technique, and that individuals with neuromuscular diseases unable to count to 20 have a SVC around $15-18 \mathrm{ml} / \mathrm{kg}$, which is indicated, performing noninvasive ventilation as an intervention technique in these patients. Despite this publication agree with the proposal of this research because count below 21 indicates the need for intervention, the said research is just one of opinion reports, and was not found in the literature studies attempting to validate the NC as an alternative to measure the SVC.

Speyer et al. ${ }^{23}$, evaluated the repeatability of MPT in a group of outpatients with functional or organic dysphonia, compared with a control group of healthy individuals. The patients presented maximum phonation times shorter compared to the control group (average 6.6 shorter). The authors concluded that the maximum phonation time proved to be a highly reliable measure in assessing voice and a single evaluator is sufficient to provide reliable measurements. This research also showed excellent intra-rater reliability for both the SVC and for the MPT with an intra-class reliability index ICC $=0.976$ for NC and ICC $=0.962$ for SVC, the main difference being the use of hospitalized individuals, and NC as a means of assessing the MPT for the measurement of SVC. Another finding of this research was that the standard error of measurement related to NC, objective evaluation of the ICC, did not represent even a drive in this way an individual account to any number would have an error in the amount of 0.8 to more or less evaluated by the same examiner.

This research suggests the use of NC as an option for the evaluation of pulmonary function of patients hospitalized in the absence of specific equipment, especially for screening those who need intervention. However, this technique should not be used to the detriment of methods already established, and doubt or suspicion of divergent outcomes, spirometry or ventilometry should be the method of choice. The ability to perform this test in any environment as clinics, the bedside and in health care is quite inspiring.

However, have included patients with different characteristics in the same analysis, it may have been a possible limitation of this study, however we sought to evaluate pulmonary functional limitation of the patient. This same proposal has been described in the literature to evaluate the SVC and indication of possible interventions in hospitalized individuals regardless of the disease, as studies of the recommendations of the Brazilian Department of Intensive Care Medicine Association of Physiotherapy ${ }^{5}$ and the European task force Respiratory Society and European Society of 
Intensive Care Medicine ${ }^{4}$. Thus, it is suggested to future studies that separately assess individuals by disease. Another issue to be considered is the possibility of time variations as a function of glottic efficiency, not necessarily in the dependence only of the SVC, or patients with glottic chink and therefore with voice impact, which may present a reduction in MPT. In order to limit these questions, patients who in the medical records or during the interview reported inflammation, infection or upper respiratory tract injury were excluded. It is important to highlight the importance of the present study, since the results described here may support research that seeks to compare individuals with the same characteristics, healthy and who can control patients with voice problems.

\section{CONCLUSION}

The importance of this study is highlighted, because $\mathrm{NC}$ is a noninvasive, fast, cheap method, that does not require the use of specific devices and only uses the voice as a resource. The present study found NC as validity and repeatability, and it may be an important screening option for assessment of lung function in the absence of specific equipment.

\section{REFERENCES}

1. Pereira CA de C, Duarte AAO, Gimenez A, Soares MR. Comparison between reference values for FVC, FEV1, and FEV1/FVC ratio in white adults in Brazil and those suggested by the Global Lung Function Initiative 2012. J bras pneumol. 2014;40(4):397-402.

2. Miller MR, Hankinson J, Brusasco V, Burgos F, Casaburi R, Coates $A$ et al. Standardisation of spirometry. Eur Respir J. 2005;26(2):319-38.

3. Heckman EJ, O'Connor GT. Pulmonary Function Tests for diagnosing lung disease. JAMA. 2015;313(22):2278.

4. Gosselink R, Bott J, Johnson M, Dean E, Nava $\mathrm{S}$, Norrenberg $\mathrm{M}$ et al. Physiotherapy for adult patients with critical illness: recommendations of the European Respiratory Society and European Society of Intensive Care Medicine Task Force on Physiotherapy for Critically III Patients. Intensive Care Med. 2008;34(7):1188-99.
5. França EET, Ferrari F, Fernandes $P$, Cavalcanti $R$, Duarte A, Martinez BP et al. Physical therapy in critically ill adult patients: recommendations from the Brazilian Association of Intensive Care Medicine Department of Physical Therapy. Rev Bras Ter Intensive. 2012;24(1):6-22.

6. Pellegrino R, Viegi G, Brusasco V, Crapo RO, Burgos F, Casaburi R et al. Interpretative strategies for lung function tests. Eur Respir J. 2005;26(5):948-68.

7. Maclntyre NR. The future of pulmonary function testing. Respir Care. 2012;57(1):154-61.

8. Ruppel GL, Enright PL. Pulmonary Function Testing. Respir Care. 2012;57(1):165-75.

9. Nygren-Bonnier M, Normi LT, Klefbeck B, Biquet G. Experiences of decreased lung function in people with cervical spinal cord injury. Disability And Rehabilitation. 2010;33(6):530-6.

10. Cardoso NFB, Araújo RC, Palmeira AC, Dias RF, França EET, Andrade FMD et al. Correlação entre o tempo máximo de fonação e a capacidade vital lenta em indivíduos hospitalizados. ASSOBRAFIR Ciência. 2013;4(3):9-17.

11. Lima DCB de, Palmeira AC, Costa EC, Mesquita FOC, Andrade FMD, Correia Junior MAV. Correlation between slow vital capacity and the maximum phonation time in healthy adults. Rev. CEFAC. 2014;16(2):592-7.

12. Palmeira AC, Escossio AL, Sarinho SW. Use of the technique of counting numbers as a predictor of slow vital capacity in hospitalized individuals. Rev. CEFAC. 2015;17(2):559-65.

13. Marfell-Jones $M$, Olds $T$, Stewart $A D$, Ridder $\mathrm{JH}$. International standards for anthropometric assessment ISAK. Potchefstroom, South Africa; 2006.

14. Zou KH, O'Malley AJ, Mauri L. Receiver-operating characteristic analysis for evaluating diagnostic tests and predictive models. Circulation. 2007;115(5):654-7.

15. Stratford PW. Getting more from the literature: estimating the standard error of measurement from reliability studies. Physiother Can. 2004;56(1):27-30.

16. Latronico N, Rasulo F. Presentation and management of ICU myopathy and neuropathy. Curr Opin Crit Care. 2010;16(2):123-7. 
17. Pinheiro AC, Novais MCM, Gomes Neto $M$, Rodrigues MVH, Rodrigues Junior ES, Aras-Junior $\mathrm{R}$ et al. Estimation of lung vital capacity before and after coronary artery bypass grafting surgery: a comparison of incentive spirometer and ventilometry. J Cardiothorac Surg. 2011;6(1):70.

18. Carvalho CRF, Paisani DM, Lunardi AC. Incentive spirometry in major surgeries: a systematic review. Rev Bras Fisioter. 2011;15(5):343-50.

19. Santos Pascotini F, Ribeiro VV, Christmann MK, Tomasi LL, Dellazzana AA, Haefner LS et al. Respiratory muscle strength, sound pressure level, and vocal acoustic parameters and waist circumference of children with different nutritional status. J Voice. 2016;30(1):30-5.
20. Rossi D, Munhoz D, Nogueira C. Relação do pico de fluxo expiratório com o tempo de fonação em pacientes asmáticos. Rev. CEFAC. 2006;8(4):509-17.

21. Izawa KP, Watanabe S, Tochimoto S, Hiraki K, Morio Y, Kasahara $\mathrm{Y}$ et al. Relation between maximum phonation time and exercise capacity in chronic heart failure patients. Eur J Phys Rehabil Med. 2012;48(4):593-9.

22. Toyoda C, Ogawa M, Oya Y, Kawai M. Maximum phonation time as a tool of screening respiratory muscle weakness in myopathic patients. No To Shinkei. 2004;56(10):873-6.

23. Speyer R, Bogaardt HCA, Passos VL, Roodenburg NP, Zumach A, Heijnen MA et al. Maximum phonation time: variability and reliability. $\mathrm{J}$ Voice. 2010;24(3):281-4. 